\title{
Tecnologias Digitais no Ensino da Matemática: Avaliações Docentes do Aplicativo Photomath
}

\author{
Daiane Leal da Conceição, Maristani Polidori Zamperetti ${ }^{2}$
}

${ }^{1}$ Doutoranda em Educação - Universidade Federal de Pelotas (UFPEL)

Cel. Alberto Rosa, 154 - Centro - 96010-770 - Pelotas - RS - Brasil

${ }^{2}$ Faculdade de Educação - Universidade Federal de Pelotas (UFPEL)

Cel. Alberto Rosa, 154 - Centro - 96010-770 - Pelotas - RS - Brasil

daianilealc@hotmail.com, maristaniz@hotmail.com

\begin{abstract}
The present work is an excerpt from the Master's Dissertation research completed, which aimed to investigate teachers' conceptions about the use of Educational Applications in the teaching of Mathematics. With a qualitative approach, the investigation was developed during the completion of the mini-course by the extension project Rede Colabora (UFPEL), that uses Moodle to promote continuing teacher education courses. The subjects of this stage were 248 mathematics teachers working in basic education. From a teaching practice developed with the Photomath Application, the results showed the contributions of using this software in the teaching of Mathematics in five aspects: pedagogical, social, behavioral, physical and evaluative.
\end{abstract}

Resumo. O presente trabalho é um recorte da pesquisa de Dissertação de Mestrado concluída, a qual teve como objetivo investigar as concepções dos docentes frente ao uso de Aplicativos Educacionais no ensino da Matemática. Com uma abordagem qualitativa a investigação foi desenvolvida durante a realização do minicurso pelo projeto de extensão Rede Colabora (UFPEL), que utiliza o Moodle para promover cursos de formação continuada de professores. Os sujeitos dessa etapa foram 248 professores de Matemática em atuação na educação básica. A partir de uma prática de ensino desenvolvida com o Aplicativo Photomath os resultados evidenciaram as contribuições do uso desse software no ensino da Matemática em cincos aspectos: pedagógico, social, comportamental, fisico e avaliativo.

\section{Introdução}

O avanço tecnológico tem possibilitado a disseminação do uso dos celulares inteligentes (smartphones) ao redor do mundo, entre crianças, jovens e adultos. Enquanto o fácil acesso à internet e telefones inteligentes pode ser muito estimulante, divertido e importante para a comunicação, expressão e criatividade na vida moderna, as desvantagens do seu uso também estão sendo observadas e documentadas. No espaço escolar observa-se um comportamento de dependência dos alunos no uso dessas tecnologias, a distração em sala de aula, com o uso dos seus smartphones, é umas das principais reclamações docentes do século XXI.

Devido à entrada dessa tecnologia no meio escolar, alguns pesquisadores incentivam o seu uso para fins educacionais. No contexto brasileiro, segundo dados do 
IBGE (2015), o uso dos smartphones cresceu muito nos últimos anos. Mais de $75 \%$ da população brasileira possui esse aparelho, incluindo crianças e adolescentes na faixa etária escolar. Entretanto, embora os dados apontem o crescimento desse uso pelos estudantes, professores e demais componentes da comunidade escolar, é comum a opinião nesse contexto de que esses dispositivos tecnológicos podem atrapalhar o aprendizado por desviarem o foco do aluno do suposto conteúdo [UNESCO 2013].

Ainda hoje, temos pais e educadores compartilhando a preocupação de que os aparelhos celulares causam distração nos alunos, levando a outros comportamentos prejudiciais como trapacear em avaliações e a facilidade no acesso ao conteúdo sexual explícito. Porém, qualquer Tecnologia da Informação e Comunicação (TIC), incluindo as tecnologias digitais móveis pode ser utilizada para acessar materiais impróprios, cabendo à família e a escola fornecer a orientação sobre o uso adequado e produtivo desses aparelhos, de modo a conscientizar os estudantes sobre o uso seguro. Diante deste contexto, segundo os autores Borba e Lacerda (2015):

Não cabe mais discutir se os celulares serão ou não utilizados na sala de aula. Eles já estão lá! Queiramos ou não. Trata-se agora de termos pesquisas, que apontem as potencialidades da utilização dos celulares inteligentes no cenário educacional [2015, p. 15]

As Tecnologias Digitais Móveis incluem qualquer tecnologia portátil e conectada, que estão em constante evolução. A diversidade de aparelhos que se encontra no mercado é imensa, e inclui, em linhas gerais, aparelhos celulares, smartphones, tablets, leitores de livros digitais (e-readers), aparelhos portáteis de áudio e controles manuais de videogames. A UNESCO (2013), ainda adota uma definição mais ampla para esses aparelhos, reconhecendo-os simplesmente como digitais, facilmente portáteis, de propriedade e controle de um indivíduo e não de uma instituição, com capacidade de acesso à internet e aspectos multimídia, possuindo inúmeras tarefas, particularmente as direcionadas a comunicação.

A disseminação do uso dessas tecnologias digitais em países desenvolvidos ocasionou um crescimento no mercado empresarial de criação de aplicativos educacionais, pois ao reconhecerem o potencial dessas tecnologias nos processos de ensino e aprendizagem passaram a desenvolver produtos a partir de uma visão comercial com uma intencionalidade lucrativa, porém carecendo de uma proposta pedagógica relevante.

Os aplicativos (Apps) educacionais são softwares, programas com funcionalidades específicas executadas em sistemas operacionais criados para os dispositivos móveis (tablets e smartphones), possuem licenças para o uso, ficando disponíveis em repositórios de empresas como, por exemplo, Google, Apple, Mozilla e Microsoft, entre outras, podendo a grande maioria serem instalados pelos usuários de forma gratuita. Diante da variedade de aplicativos disponíveis no mercado, cabe ao professor, realizar uma seleção, embasando suas escolhas em função dos objetivos que se pretende atingir pedagogicamente e das concepções de conhecimento e aprendizagem que orienta o seu processo.

Hoje, vários (Apps) matemáticos estão disponíveis para smartphones onde mostram passo a passo como resolver determinados problemas e desafios. Porém, na área da Educação Matemática ainda encontram-se poucas pesquisas que revelem o 
potencial desses aplicativos nos processos de ensino e aprendizagem, principalmente na visão dos professores que estão em atuação na educação básica.

Desta forma, diante da temática apresentada essa pesquisa de Mestrado em Educação desenvolvida em 2017/2018, na área de Formação de Professores, pelo curso de pós-graduação em Educação da Universidade Federal de Pelotas (UFPEL) teve como objetivo geral: Investigar as concepções dos docentes frente às potencialidades do uso do Aplicativo Photomath (veiculado pelos smartphones) no ensino da Matemática.

Nesse recorte da investigação serão apresentadas as avaliações docentes frente ao uso do Aplicativo Photomath em sala de aula. Sendo este grupo formado por 248 professores de Matemática em atuação na educação básica da rede pública brasileira. A pesquisa teve apoio teórico no campo da Mobile Learning as concepções de Traxler (2005) e Moura (2010) e as discussões acerca do uso dos Apps na educação nos estudos de Saccol e Schlemmer (2011), Dias e Araújo Jr (2012) e Figueiredo (2005).

Com uma abordagem qualitativa, foi desenvolvida durante a realização do minicurso "O uso de smartphones no ensino da Matemática", pelo projeto de extensão Rede Colabora da UFPEL, que utiliza o Ambiente Virtual de Aprendizagem (Moodle) para promover cursos de formação docente para o uso das Tecnologias de Informação e Comunicação (TIC), na modalidade de Educação a Distância (EAD).

\section{Desenvolvimento da Pesquisa}

No atual cenário educacional brasileiro existe a proibição do uso de aparelhos celulares ou restrições de uso no ambiente de sala de aula em instituições públicas, amparadas por legislações estaduais, conforme o art. $1^{\circ}$ da Constituição do Estado do Rio Grande do Sul (Lei $n^{0}$ 12.884, de 03 de Janeiro de 2008) em que dispõe sobre a utilização de aparelhos de telefonia celular nos estabelecimentos de ensino, devido à ocorrência de um número elevado de confrontos entre alunos, professores e administrações escolares, causados pelo uso inadequado dessa tecnologia, segundo a visão destas instituições.

Porém, na possibilidade de transformar esses aparelhos em tecnologias educacionais que podem vir a potencializar o processo de construção de conhecimentos matemáticos, utilizando uma abordagem qualitativa, essa investigação se propôs a responder o seguinte questionamento: Nas concepções dos docentes em que aspectos o uso de Apps Educacionais podem contribuir para o ensino da Matemática?

Bicudo (1993) ressalta que nesta abordagem, pesquisar requer a busca pelas compreensões e interpretações significativas para uma pergunta e também a busca por explicações cada vez mais convincentes sobre tal questão. Portanto, a abordagem qualitativa no desenvolvimento dessa investigação visou criar um espaço permanente de compreensão, reflexão e de análise das discussões e práticas pedagógicas que emergiram da interação dos professores com uma tecnologia digital móvel (smartphones), oportunizada pela participação em um minicurso online, totalmente à distância, ofertado pelo um projeto de extensão da Universidade Federal de Pelotas (UFPEL).

A pesquisa foi desenvolvida em um Ambiente Virtual de Aprendizagem (Moodle Institucional), durante a realização da $1^{\text {a }}$ Edição do minicurso intitulado, "O uso do smartphone no ensino da Matemática". O minicurso foi promovido pelo Projeto 
de Extensão Rede Colaboral que utiliza o Moodle para promover cursos de formação docente para o uso das TIC, na modalidade EAD. Com a proposta de um minicurso oferecido totalmente à distância, o convite de participação em formato de vídeo se expandiu por todo o território brasileiro, através da divulgação em redes sociais, ocasionando na homologação de 662 inscrições de professores de Matemática, em atuação na educação básica das redes públicas de ensino do país (figura 1). Sendo 241 professores de rede Municipal, 385 da rede Estadual e 36 de Institutos Federais.

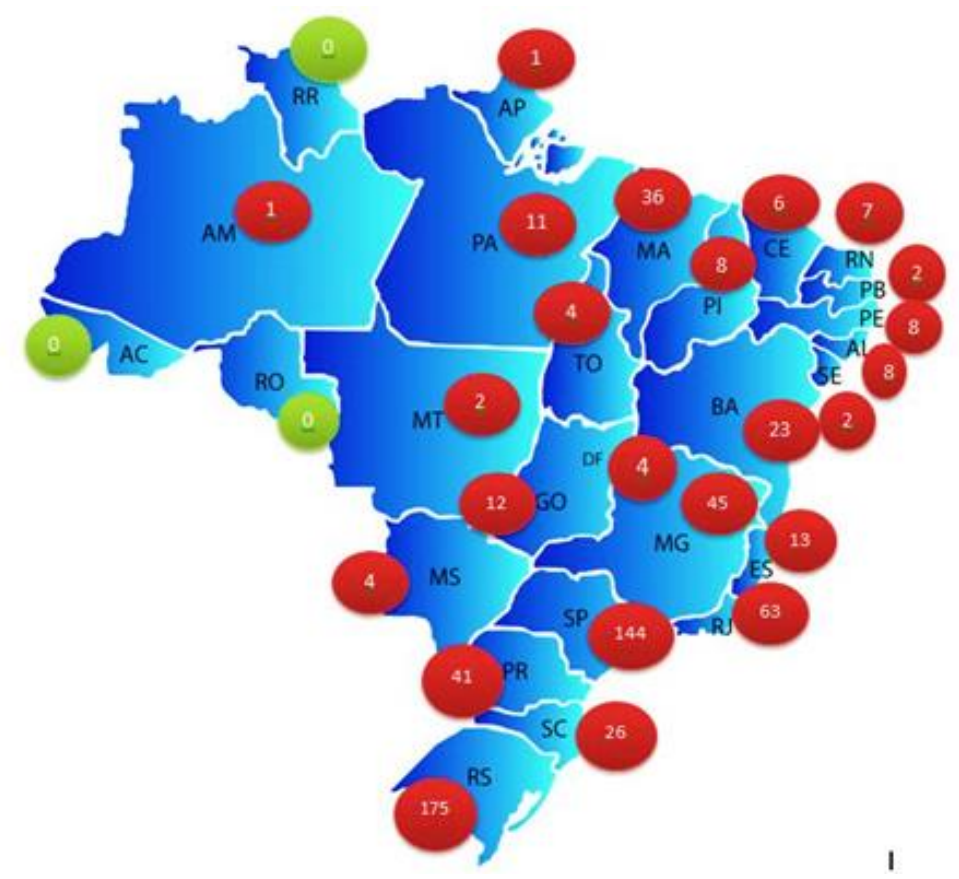

Figura 1. Inscrições nacionais. Fonte: dados da pesquisa.

O minicurso foi organizado em quatro módulos, dividido em cinco semanas do mês de agosto/2017 para atividades teóricas e atividades práticas a serem desenvolvidas nos meses de setembro e outubro/2017. Durante o seu desenvolvimento foram apresentados cincos aplicativos educacionais gratuitos, disponíveis para download para Android na Google play e para dispositivos iOS da Apple na App Store: Photomath2, Mathematics, Calculadora Gráfica Geogebra, Mathway e Truques Matemáticos. Foi proposto aos docentes explorar e avaliar as funcionalidades dos apps, compartilhando as suas opiniões com os colegas no fórum de discussões na plataforma moodle e na narrativa digital produzida após a aula prática planejada e desenvolvida em suas escolas com o App. PhotoMath (Figura 2). Concluíram o minicurso e receberam a certificação

\footnotetext{
${ }^{1}$ A Rede Colabora é um Programa de Extensão de uma Universidade Federal do país, financiado pelo Ministério da Educação, criado em 2014, que visa incentivar o uso das TIC no ensino, em parceria com escolas públicas do país, acompanhando e auxiliando os professores na inclusão dessas tecnologias em suas práticas a partir da oferta de cursos básicos de formação continuada, através da Educação a Distância (EaD).

${ }^{2}$ Aplicativo PhotoMath, criado pela Empresa Microblink, o app tem uma base de dados com inúmeros conteúdos matemáticos, números inteiros, frações, números decimais, raízes, expressões algébricas, equações; inequações lineares, equações e inequações abstratas, sistemas de equações, logaritmos, trigonometria, funções exponenciais e logarítmicas, derivadas e integrais, entre outros, apresentando ao usuário além da resposta final, todo o desenvolvimento do cálculo. Disponível para download em: https://photomath.net/en/\#download. Acesso em: 15 mar. 2018.
} 
de participação de 40hs emitida pela Pró-Reitoria de Extensão da Universidade 248 professores de Matemática que com autorização prévia se tornaram participantes dessa pesquisa de Mestrado.

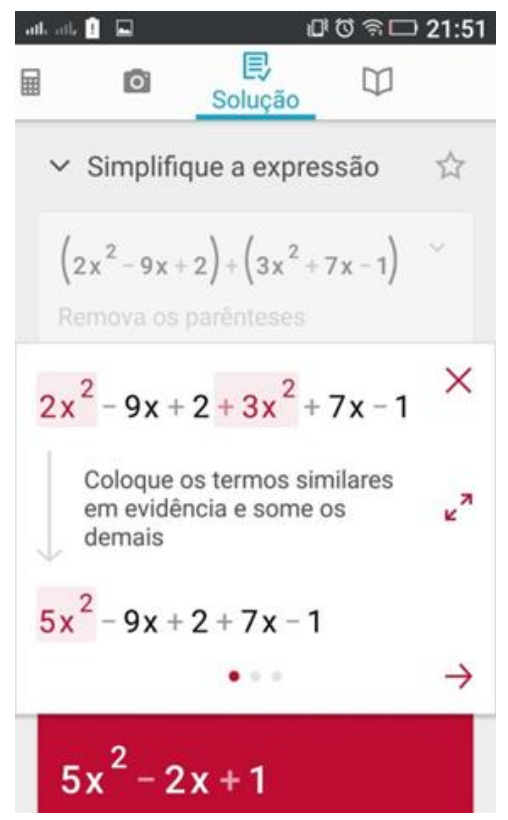

Figura 2. Captura do layout do App PhotoMath, disponível em: https://photomath.net/en/

\subsection{Fontes de Dados}

Para o desenvolvimento da pesquisa foram utilizados variados instrumentos e procedimentos para obtenção de dados, com o objetivo de reunir o máximo de informações possíveis sobre o objeto de estudo. Em uma abordagem qualitativa a utilização de diferentes procedimentos que possibilite o confronto de dados, contribuiu para o aumento da credibilidade de pesquisa (Alves-Mazzotti, 1998). Assim, diante das particularidades do lócus da investigação e o número elevado de professores participantes foram considerados apropriados os seguintes instrumentos de produção de dados durante o desenvolvimento do minicurso: Questionários online, Fórum de dúvidas e discussões no Moodle, Planos de aula e Narrativas Digitais.

A participação de docentes de diferentes regiões do país inviabilizou a observação das práticas de ensino desenvolvidas por eles como atividade final da formação. Desta forma, foi proposta como atividade o registro dessas práticas por meio da produção de "Narrativas Digitais", com o objetivo de identificar a intencionalidade do uso do app no ensino da Matemática, atribuídas pelos docentes, conteúdos matemáticos que foram explorados e as possibilidades e limitações do App Photomath. Almeida e Valente (2012), definem as Narrativas Digitais como:

Uma forma de registrar e relatar uma experiência por meio das quais os alunos registram os caminhos adotados em suas buscas, as informações levantadas, suas produções e descobertas. Esses aspectos são significativos em processos educativos pautados pelo exercício da autoria do aprendiz por meio da construção, análise e reconstrução de 
suas histórias, permitindo registrar sua trajetória epistemológica e organizar os modos de pensar sobre as experiências e as relações que estabelece consigo mesmo e com o mundo, podendo contar com a colaboração de outras pessoas [ALMEIDA, VALENTE 2012, p.6].

\subsection{Análise de Dados}

Após o encerramento do minicurso, obteve-se um banco de dados com o registro da participação de 451 professores, embora somente 248 tenham concluído o curso completo. Para desenvolver esse processo, foram utilizados os princípios da "Análise do conteúdo" de Bardin (1979), pois segundo Minayo (2006) em uma perspectiva qualitativa os pesquisadores buscam:

[...] a compreensão dos significados no contexto da fala, em geral, negam e criticam a análise de frequências das falas e palavras com critérios de objetividade e cientificidade e tentam ultrapassar o alcance meramente descritivo da mensagem para atingir, mediante interferência, uma interpretação mais profunda (p.307).

Dessa forma, a análise dos dados coletados foi desenvolvida em três etapas:

I. Organização os dados obtidos em tabelas e gráficos;

II. Realização da categorização dos dados, desenvolvendo um processo de construção das categorias a partir da interpretação do conteúdo contido nos depoimentos dos sujeitos [MINAYO 2007]

III. Interpretação dos resultados encontrados na descrição das categorizações com o auxílio da fundamentação teórica;

Após a observação dos dados obtidos e a descrição das relações encontradas, três categorias de análise foram concebidas: a) A relação dos docentes com as Tecnologias Digitais Móveis; b) Os Apps Educacionais em avaliações docentes; c) As práticas docentes com Apps Educacionais. Esse artigo detém-se a apresentar os resultados encontrados na segunda categoria.

\section{Resultados e Discussões}

Diante da variedade de aplicativos disponíveis para download no mercado com propostas educacionais, cabe ao professor realizar uma análise sobre a qualidade desses apps, de acordo com os objetivos que pretende atingir ao utilizar essa tecnologia em sala de aula. Segundo Morgado et al (2013), para que um aplicativo seja considerado educativo, deve não apenas facilitar o ensino, mas também promover a aprendizagem.

Teve o aporte teórico as avaliações realizadas pelos docentes do aplicativo Photomath os requisitos e atributos dos apps educacionais apresentados no minicurso na visão dos autores Dias; Araújo Jr (2012), Figueiredo (2005) e Sacool et al (2011): "pedagógico, usabilidade, interatividade, acessibilidade, flexibilidade, mobilidade, ubiquidade, colaboração, compartilhamento, e reusabilidade."

Conforme Schlemmer (2007), um aplicativo não deve, obrigatoriamente, conter todos os requisitos apresentados nesse estudo, e sim, ter a qualidade necessária para o alcance de seus propósitos e satisfação de seus usuários. Portanto, entende-se que o professor ao selecionar um aplicativo para ser usado em sala de aula, necessita embasar 
suar escolhas em função dos objetivos que pretende atingir pedagogicamente e das concepções de conhecimento e aprendizagem que vão orientar esse processo de inserção.

Os grifos realizados nas falas dos docentes no quadro abaixo correspondem a algumas repercussões que o uso do App. Photomath teve na prática de sala de aula desenvolvida pelos professores de Matemática:

Quadro 1. Avaliações docentes das práticas com Aplicativo Photomath (grifo da autora).

\begin{tabular}{|c|}
\hline Avaliaçóes docentes das práticas com Aplicativo Photomath \\
\hline $\begin{array}{l}\text { "Os alunos adoraram as atividades e ficaram impressionados com os resultados. A aula foi muito produtiva e } \\
\text { interessante, o uso do smartphone contribuiu para o entendimento do conteúdo. Eles não tiveram maiores } \\
\text { dificuldades no uso do App. As atividades realizadas mostrou-nos que o professore um mediador de ensino e } \\
\text { aprendizagem, devemos sempre buscar novas formas de conhecimento e acompanhar as tecnologias" } \\
\text { (Prof_Municipal_AS). }\end{array}$ \\
\hline $\begin{array}{l}\text { "O aplicativo trouxe interatividade para a aula de produtos notáveis. Os alunos gostaram muito, viram como } \\
\text { uma possibilidade de obter informaçôes relevantes na hora de fazer o cálculo. A aula com recursos digitais é } \\
\text { sempre mais atrativa, os alunos adoram e eu particularmente prefiro. Pena que o aplicativo não plota o produto } \\
\text { notável geometricamente como a soma das áreas, mas com a conta os alunos puderam desenhar o quadrado } \\
\text { maior baseado nas respostas do aplicativo."(Prof_Estadual_CL). }\end{array}$ \\
\hline $\begin{array}{l}\text { "Com a utilização do aplicativo aliado às atividades propostas foi observado aumento significativo na } \\
\text { participação e na aprendizagem dos alunos, uma vez que construindo os gráficos da função eles puderam } \\
\text { interagir com o celular, aumentando a sua compreensão" (Prof_Estadual_CW). }\end{array}$ \\
\hline $\begin{array}{l}\text { "A atividade com o aplicativo Photomath foi muito significativa para os alunos, que ficaram entusiasmados } \\
\text { com a utilização de um aplicativo para conferência de resultados e também para entendimento de res oluçães. A } \\
\text { participação dos alunos foi excelente, ficando sempre atentos a todos os passos da aula. Percebe-se que } \\
\text { quando temos atividade diferenciada, o ensinoe a aprendizagem também acontece de forma diferenciada, pois } \\
\text { os alunos sentem-se motivados e desafiados." (Prof_Municipal_CS). }\end{array}$ \\
\hline $\begin{array}{l}\text { “Eu como professora gostei muito de ver a dinamização em sala de aula com o uso do ap licativo. Ver a carinha } \\
\text { deles de felicidade ao usar o aplicativo foi muito gratificante. A utilização de materiais diferenciados propicia } \\
\text { uma nova alternativa de aprendizagem, visando auxiliar o aluno na assimilação de conceitos. Por esse } \\
\text { motivo, a partir dessa aula, foi possível perceber a importância de conhecer novos métodos de ensino } \\
\text { aprendizagem” (Prof_Municipal_LS). }\end{array}$ \\
\hline $\begin{array}{l}\text { "A aula decorreu como planejado, os alunos que foram participaram (havia avisado previamente pelo e-mail da } \\
\text { turma para levassem alguns materiais que seriam utilizados na aula), o que me impressionou foi o silêncio e } \\
\text { o espírito colaborativo entre eles, questionando se estavam certos ou não. Foi um momento para mim } \\
\text { muito prazeroso, pois conseguiver que as aulas de matemática podem ser feita além do quadro e livro. Como } \\
\text { conclusão, pensarei em mais atividade com os alunos com a utilização de outros aplicativos, pois a } \\
\text { concentração e o resultado obtido foram positivos, gerando uma discussão e colaboração entre a turma" } \\
\text { (Prof_Federal_ML). }\end{array}$ \\
\hline
\end{tabular}

No primeiro destaque, "o professor é um mediador de ensino e aprendizagem", o professor não esclarece a concepção que tem da palavra mediação, porém atribui um novo significado ao seu papel como docente nessa prática de ensino com a utilização dessa tecnologia.

No segundo grifo "Os alunos se sentiram atraídos", o professor relata que o uso dessa tecnologia atraiu a participação dos alunos para a atividade proposta, complementado pela fala do Prof_Estadual_CL, ao destacar que "o aplicativo trouxe interatividade para a aula de produtos notáveis", um conteúdo do $8^{\circ}$ ano do Ensino Fundamental em que álgebra se faz presente e o ensino de conceitos abstratos acabam deixando a Matemática pouco palpável para os alunos, desestimulando, assim, o interesse pela disciplina. Desta forma a interatividade proporcionada pelo aplicativo, trouxe na fala do professor a observação do "aumento significativo na participação dos alunos" em aula.

Nessa mesma análise da repercussão do uso do app em sala de aula, destaco a fala do Prof_Federal_ML, "o que me impressionou foi o silêncio e o espírito colaborativo entre eles, questionando se estavam certos ou não", pois além do aumento da participação o professor observou a interação dos estudantes na resolução das 
atividades propostas de forma que a atenção dada às atividades modificou o comportamento habitual dos alunos nessa disciplina.

O último grifo retirado da fala do Prof_Municipal_LS, "a utilização de materiais diferenciados propicia uma nova alternativa de aprendizagem, visando auxiliar o aluno na assimilação de conceitos. Por esse motivo, a partir dessa aula, foi possível perceber a importância de conhecer novos métodos de ensino e aprendizagem" é um destaque que serve para desmistificar a concepção de uso de uma tecnologia digital em sala de aula, observa-se, nessa fala, que o professor vê o uso das TIC como uma metodologia, nesse caso, os aplicativos são softwares que podem vir a potencializar a construção de conceitos e não um método de ensino ou aprendizagem.

Questionar o porquê da inserção das TIC, e como estamos inserindo em nossas práticas é importante na concepção de Rosa (2011), para que o professor compreenda que argumentos como motivação ("o computador motiva o aluno!"), demanda social ("a sociedade exige que se usem tecnologias"), facilidade ("as TIC facilitam a vida do aluno"), falta de enquadramento ("há disciplinas que não permitem o uso de TIC"), entre outros, já não justificam o uso de tecnologias no ambiente educacional. Tal fato é afirmado, pois tais argumentos são reveladores de ações que não se ligam diretamente ao objetivo central da educação a produção do conhecimento por parte do estudante.

Para Rosa (2011), a motivação é algo intrínseco ao ser humano, não há como garantir que qualquer máquina motive, uma vez que, se ela motiva, motivaria todos os estudantes em qualquer momento. Afirma ainda, ser impossível garantir que uma máquina, por mais tecnológica que seja, motive qualquer aluno, pois essa motivação é algo intrínseco a cada estudante. Ainda para Freire e Shor (1986), a motivação é um momento da própria ação, o sujeito se motiva à medida que está atuando, a motivação tem que estar dentro do próprio ato de estudar, no reconhecimento do sujeito da importância do conhecimento. Assim, podemos crer que aspectos ligados à motivação do aluno, ou a facilidades que as tecnologias proporcionam, são fatores que sozinhos não podem justificar o uso de TIC na sala de aula, pois há uma a necessidade, segundo o referencial teórico abordado neste estudo, do uso ser justificado, teórico e metodologicamente, para que o potencial dessa tecnologia seja explorado, visando ao favorecimento da construção do conhecimento pelo discente.

Cabe ainda ressaltar que o estudo analisou os relatos docentes de uma prática incipiente. Nessa prática os professores participantes apontaram nove (09) potencialidades do uso app no ensino da Matemática: potencializa a compreensão de conceitos, possibilitando introduzir e/ou fixar conteúdo e permitindo a correção imediata de exercícios. O app permite a visualização de distintas representações matemáticas e a exploração e recuperação paralela de conteúdos, incluindo conteúdos avançados. Além disso, promove o compartilhamento das resoluções e a edição e criação de dados, possuindo uma interface acessível e oportunizando a investigação Matemática, podendo ser usado em diferentes níveis de ensino.

Essas potencialidades atribuídas pelos docentes forneceram indícios que o uso do App Photomath em sala de aula, pode vir a contribuir para o ensino da Matemática em cinco aspectos, em resposta ao questionamento inicial dessa investigação: no aspecto pedagógico - a resolução dos cálculos apresentada pelo aplicativo e a interface de fácil manuseio e entendimento viabilizou o tempo de aula para atividades de resolução de problemas e discussões de resultados. No aspecto social - as interações 
dos alunos com os aplicativos educacionais oportunizaram atividades em grupo, oportunizando as discussões de resultados e resoluções entre aluno $\mathrm{x}$ aluno e aluno e professor. O aspecto comportamental - os professores evidenciaram que o uso dos aplicativos motivou a participação dos alunos, despertando o interesse pelo conteúdo matemático que estava sendo trabalhado. No que tange aos aspectos físicos - os professores viram a possibilidade de utilizar os aplicativos como apoio as tarefas propostas para casa, propondo o estudo em outros ambientes, dentro desse aspecto também foi identificado que ao trabalhar com os aplicativos não são necessárias estruturas físicas como laboratórios de informática. E por último, quanto ao aspecto avaliativo - foi observada a autonomia que os alunos adquiriram na correção de tarefas a partir do feedback imediato dado pelo app, otimizando o tempo de aula que era gasto para correção no quadro. Nesse aspecto os professores vislumbraram a oportunidade de avaliação pela funcionalidade de compartilhamento de resoluções disponível no aplicativo.

\section{Conclusões Finais}

Além, dos aspectos apresentados, em relação à formação de professores, foi possível concluir nesse estudo que os docentes estão em busca por práticas de ensino diferenciadas. E considerando as abordagens de Bicudo (1993) e Rosa (2011), estas práticas necessitam de uma aproximação com o contexto de formação do professor para o uso das tecnologias digitais.

Necessita-se entender que essa formação é contínua e inacabada e se encontra em diferentes modalidades, em constante e permanente transformação, de forma a contemplar tecnologias que surgem diariamente, abarcando ideias dos próprios estudantes e se lançando ao risco de não deter o controle absoluto sobre elas. Ou seja, formando-se inicialmente na ideia que as TD não são meros suportes ou recursos, mas que atuam conjuntamente com cada um e com o coletivo, para que as inovações da prática pedagógica aconteçam naturalmente.

A universidade além da produção de novos conhecimentos tem como função a disseminação desses conhecimentos para a comunidade. Dessa forma tanto o Programa de Extensão Rede Colabora quanto a pesquisa foram beneficiados com a colaboração dos professores participantes. A universidade, por oferecer um novo curso, solicitado pelos próprios docentes e Rede Colabora por beneficiar-se de toda a infraestrutura existente do projeto de extensão da universidade, divulgando e colaborando com a execução desta pesquisa. $O$ princípio da indissociabilidade entre a pesquisa e a extensão refletiu na qualidade do trabalho acadêmico, favorecendo a aproximação entre universidade e sociedade.

Essa investigação apresenta-se como um convite à reflexão sobre o uso de aplicativos educacionais no ensino da Matemática a partir de concepções docentes, sem apresentar soluções imediatas e pontuais em relação à proibição do uso de aparelhos celulares nas escolas, e sim apresentar potencialidades identificadas por professores em atuação nesse contexto.

\section{REFERÊNCIAS}


Almeida, M. B.T.; Valente, J. A.(2012). ALMEIDA, M. B.T.; VALENTE, J. A. "Integração currículo e tecnologias e a produção de narrativas digitais". Currículo sem Fronteiras, v. 12, n. 3, p. 57---82, Set/Dez 2012. Disponível em: http://www.curriculosemfronteiras.org/vol12iss3articles/almeida---valente.pdf Janeiro.

Bardin, L.(1979). “Análise de Conteúdo”. Lisboa: Edições 70.

Bicudo, M. A. V.(1993). "Pesquisa em educação matemática". Revista Proposições. Campinas, v.4, n.1, p.1823.

Borba, M. C.; Lacerda; H. D. G.(2015). "Políticas públicas e tecnologias digitais: um celular por aluno." In: III Fórum de Discussão: Parâmetros Balizadores da Pesquisa em Educação Matemática no Brasil. v.17, p.490-507.

Dias, E. J.; Araújo Jr., C. F. (2012) "Mobile Learning no Ensino de Matemática: um framework conceitual para uso dos tablets na educação básica." In: Encontro de produção discente PUCSP/Cruzeiro do Sul. 2012, São Paulo. Anais. São Paulo, 2012, p. 1-13

Freire, P.; Shor, I. (1986). "Medo e ousadia: o cotidiano do professor." 2. ed. Rio de Janeiro: Paz e Terra,

Figueiredo, C. X. (2015) “Avaliação de software educacional”. Lavras: Universidade Federal de Lavras.

Ibge. (2015). "Pesquisa Nacional por Amostras de Domicílio: Acesso à Internet e à Televisão e Posse de Telefone Móvel Celular para Uso Pessoal." Rio de Janeiro/Brasil.

Lüdke, M.; André, M. E. D. A.(1986). "Pesquisa em educação: abordagens qualitativas." São Paulo: EPU.

Minayo, M. C. S.(1994). "O desafio do conhecimento: pesquisa qualitativa em saúde." São Paulo: Hucitec.

Moura, A.(2010) "Apropriação do Telemóvel como Ferramenta de Mediação em Mobile Learning: Estudos de Caso em Contexto Educativo.” 2010. p.630 Tese (Doutorado Ciências da Educação). Programa de Pós-Graduação em Tecnologia Educativa. Braga: Universidade do Minho.

Rio Grande do Sul. "Lei do celular." Disponivel em: http://www.al.rs.gov.br/filerepository/repLegis/arquivos/12.884.pdf. Novembro.

Rosa, M. (2008). "A construção de identidades online por meio do Role Playing Game: relações com o ensino e a aprendizagem de matemática em um curso a distância." Tese (Doutorado em Educação Matemática) - UNESP, Rio Claro.

Saccol, A., Schlemmer, E. Barbosa, J.(2011) "M-learning e u-learning: novas perspectivas das aprendizagens móvel e ubíqua." São Paulo: Pearson Prentice Hall,

Traxler, J. (2005). "Institutional Issues: Embedding and Supporting." In A. KukulskaHulme, \& J. Traxler (Eds.) Mobile Learning: A Handbook for Educators and Trainers (pp. 173-188). London: Routledge.

Unesco(2014). "Policy Guidelines for Mobile Learning. O Futuro da aprendizagem móvel: implicações para planejadores e gestores de políticas”. Brasília. 